\title{
Room Temperature Activates Human Blood Platelets
}

\author{
Elisabeth Maurer-Spurej, Gisela Pfeiler, Norbert Maurer, Helmut Lindner, \\ Otto Glatter, and Dana V. Devine
}

Canadian Blood Services (EM-S, DVD), Vancouver; Department of Pathology (EM-S, DVD), University of British
Columbia, Vancouver, British Columbia, Canada; Department of Histology (GP), University of Graz, Graz, Austria;
Department of Biochemistry and Molecular Biology (NM), University of British Columbia, Vancouver, British
Columbia, Canada; and Department of Physical Chemistry (HL, OG), University of Graz, Graz, Austria

SUMMARY: Temperatures ranging from room temperature $\left(20^{\circ} \mathrm{C}\right)$ to $42^{\circ} \mathrm{C}$ are generally not considered to have an activating effect on platelets. However, this assumption is not supported by clinical phenomena that result in hemostatic failure related to hypothermia. In this study, we investigated the effect of temperatures between room temperature $\left(20^{\circ} \mathrm{C}\right)$ and $42^{\circ} \mathrm{C}$ on human blood platelets and found that room temperature causes marked activation of platelets. Major changes in platelet morphology were seen at $20^{\circ} \mathrm{C}$ compared to resting platelets at $37^{\circ} \mathrm{C}$. Platelet morphology was investigated with noninvasive live cell techniques (light microscopy and dynamic and static light scattering), as well as with transmission and scanning electron microscopy. The changes in platelet morphology correlated with the expression of the activation marker, activated glycoprotein (GP) Ilb-IIla, measured by flow cytometry. Twenty-five percent to $30 \%$ of platelets expressed activated GPIlb-IIla after exposure to $20^{\circ} \mathrm{C}$ for 10 minutes. In the presence of serotonin re-uptake inhibitors, the serotonin content of platelets at $20^{\circ} \mathrm{C}$ was twice that of resting platelets. In comparison, moderate heat shock conditions ( $42^{\circ} \mathrm{C}$ for 10 minutes) caused no signs of platelet activation as indicated by the absence of morphological alterations, no expression of activated GPIlb-IIla, and no changes in serotonin content. These results show that room temperature by itself significantly activates platelets and has an effect on the platelet serotonin content. This may contribute to both the functional lesion associated with $22^{\circ} \mathrm{C}$ storage of platelets for transfusion and the in vivo hemostatic failure after hypothermia. (Lab Invest 2001, 81:581-592).

$U$ nder many physiological, pathophysiological, ex vivo, and laboratory conditions, platelets are subjected to temperatures below and above $37^{\circ} \mathrm{C}$. For research purposes or the production of platelet concentrates for transfusion, platelets are isolated from whole blood at room temperature or lower. In blood banks platelet concentrates are stored at $20^{\circ} \mathrm{C}$ to $24^{\circ} \mathrm{C}$ (Murphy and Gardner, 1969). In the peripheral circulation or in situations of hypothermia caused by trauma or extracorporeal circulation, platelets may encounter temperatures significantly lower than $37^{\circ} \mathrm{C}$ (Boldt et al, 1996). On the other hand, whole-body hyperthermia with an increase of the body core temperature to $41.8^{\circ} \mathrm{C}$ was reported in cancer treatment (Pereira Arias et al, 1999). Therefore, a temperature range of $20^{\circ} \mathrm{C}$ to $42^{\circ} \mathrm{C}$ might be considered clinically relevant. However, the effects of hypo- and hyperthermia on platelets and platelet function are not well understood.

It is well recognized that the exposure of platelets to $4^{\circ} \mathrm{C}$ results in platelet activation (White and Krivit, 1967; Zucker and Borrelli, 1954). Activation of chilled

Received January 11, 2001.

The work was funded by the Canadian Blood Services and the Österreichischen Fonds zur Förderung der Wissenschaftlichen Forschung (Project Nos. P6741-CHE and P12611-CHE).

Address reprint requests to: Dr. Elisabeth Maurer-Spurej, University of British Columbia, Department of Pathology, 2211 Wesbrook Mall, Vancouver, BC, CanadaV6T2B5. E-mail: emaurer@interchange.ubc.ca platelets $\left(4^{\circ} \mathrm{C}\right)$ was observed as a morphological change from the resting discoid state (Bizzozero, 1865; White, 1991; Zucker and Borrelli, 1954) to activated spherical cells with pseudopods. It has also been shown that the morphological changes in chilled platelets are accompanied by a rise of intracellular calcium concentrations (Milton et al, 1985). The molecular mechanism of shape change induced by chilling is still under dispute in the literature. Winokur and Hartwig (1995) discovered that the morphological changes are due to rearrangements of actin filaments. White and Krivit (1967) and White and Rao (1998) reported that the loss of the circumferential microtubules is responsible for the shape change in chilled platelets because the microtubules maintain the discoid shape of resting platelets. This question is the subject of ongoing research and demonstrates that the temperature effects on platelets are far from being understood. Although the results obtained from chilled platelets give valuable insight into the physiology of platelets at low temperature, $4^{\circ} \mathrm{C}$ is a temperature far below the clinically relevant temperatures for hypothermia.

The detrimental effects of refrigeration on the storage of platelet concentrates have been recognized. Murphy and Gardner (1969) showed that the in vivo survival time of platelets from platelet concentrates was significantly lower when platelets were stored at $4^{\circ} \mathrm{C}$ compared with platelets stored at $20^{\circ} \mathrm{C}$. These results led to the currently used storage temperature of $20^{\circ} \mathrm{C}$ to $24^{\circ} \mathrm{C}$ in blood banks. During the standard 
5-day storage at room temperature, platelets demonstrate a loss of their integrity and functionality known as the platelet storage lesion. Whether the low temperature during preparation and storage of platelet concentrates in part causes the platelet storage lesion is not known.

In the literature, controversial results on the effect of room temperature on platelets can be found. Tablin et al (1996) reported a phase transition temperature of the platelet plasma membrane of $15^{\circ} \mathrm{C}$ to $18^{\circ} \mathrm{C}$ measured with Fourier transform infrared spectroscopy. They suggested that the lipid phase transition may be related to platelet activation. Michelson et al (1994, 1999) reported that, in the absence of an agonist, room temperature (hypothermia) alone has an inhibitory, rather than an activating, effect on platelet function and concluded that this reduced platelet activity is causing the coagulopathy associated with hypothermia. Faraday and Rosenfeld (1998) hold a contrary view. They found enhanced activation of glycoprotein IIb-IIIa (GPIIb-IIla) and $\alpha$-granule release when platelets were activated with ADP after exposure to $22^{\circ} \mathrm{C}$, compared with platelets kept at $37^{\circ} \mathrm{C}$. However, they reported that temperature alone had no effect on platelet activation. In a few other studies, morphological changes of platelets induced by room temperature have been observed (Breddin et al, 1975; Milton et al, 1985; Nachmias, 1980).

Temperatures up to $42^{\circ} \mathrm{C}$ were found to have no effect on platelet morphology (Rao et al, 1993; White, 1968). This is in contrast to other cells that respond to high temperature with surface blebbing (Zatloukal et al, 1988). The effect of hyperthermia on the expression of platelet activation markers or the platelet serotonin content in the presence of re-uptake inhibitors has not been previously investigated. It was, however, reported that the number of unactivated GPIIb-IIla molecules decreases on the platelet surface when the temperature exceeds $40^{\circ} \mathrm{C}$ (Pasha et al, 1995).

The objective of this study was to gain a better understanding of the effects of temperature on platelet activation. Platelet morphology was investigated together with biochemical parameters such as the surface expression of activation markers and release of granule contents. Hypothermia caused severe morphological changes, the expression of activated GPIIb-IIla, and changes in serotonin content. The temperature-induced activation of platelets shared features in common with that induced by chemical agonists such as thrombin but was distinct in that it was not accompanied by $\alpha$-granule release. The results presented here demonstrate that platelets are activated at room temperature, a much higher temperature than previously reported in the literature.

\section{Results}

We investigated the direct effects of different temperatures on platelet activation without the addition of agonists. Morphological changes were observed with microscopy and light scattering techniques. Flow cytometry was used for the detection of activation mark- ers on the platelet plasma membrane. For the measurement of the serotonin (5-hydroxytryptamine, 5-HT) concentration, we used high-pressure liquid chromatography (HPLC) or a serotonin ELISA. Platelet serotonin was also visualized with fluorescence microscopy.

Clinically, platelets are exposed to a temperature range from $20^{\circ} \mathrm{C}$ to $42^{\circ} \mathrm{C}$. This report is limited mainly to the extremes of that temperature range, $20^{\circ} \mathrm{C}$ and $42^{\circ} \mathrm{C}$, in comparison with the normothermic control at $37^{\circ} \mathrm{C}$.

\section{Temperature Induced Activation of Platelets: Phase Contrast and Electron Microscopy}

Lowering the temperature of platelet suspensions from $37^{\circ} \mathrm{C}$ to $20^{\circ} \mathrm{C}$ caused distinct morphological changes. The first column in Figure 1 (A to $C$ ) shows phase contrast micrographs of live platelets. The use of a light microscope equipped with a digital camera and a temperature stage allowed the monitoring of the effects of temperature on live platelets in real time. Discoid platelets can be seen at $42^{\circ} \mathrm{C}(\mathrm{A})$ and $37^{\circ} \mathrm{C}$ (B), and morphologically changed platelets at $20^{\circ} \mathrm{C}$ (C). The three pictures are frames taken from a realtime recording of platelet-rich plasma (PRP) subjected to temperatures between $42^{\circ} \mathrm{C}$ and $20^{\circ} \mathrm{C}$. Scanning ( $D$ to $F$ ) and transmission electron microscopy studies ( $G$ to I) are in agreement with these findings as shown in Figure 1. Ultrastructural changes were visualized by transmission electron microscopy. Platelets at $42^{\circ} \mathrm{C}$ $(\mathrm{G})$, as well as at $37^{\circ} \mathrm{C}(\mathrm{H})$, have intact circumferential microtubules. These structures centralize and disappear from many platelets incubated at $20^{\circ} \mathrm{C}$ (I). Platelets were incubated at $20^{\circ} \mathrm{C}$ for 10 minutes. We demonstrate here that temperature activation of platelets is very pronounced at room temperature, whereas it was previously shown to occur only at temperatures below $20^{\circ} \mathrm{C}$. Platelets are sensitive to temperatures between $37^{\circ} \mathrm{C}$ and $20^{\circ} \mathrm{C}$ (hypothermia) but not to physiologically relevant high temperatures (hyperthermia). The pictures shown in Figure 1 are representative of at least five similar sets.

We also observed that the morphological changes at $20^{\circ} \mathrm{C}$ were dependent on the anticoagulant. Platelets prepared from acid citrate dextrose (ACD, $\mathrm{pH}$ 6.0)-anticoagulated blood showed significantly fewer signs of activation after 10 minutes at $20^{\circ} \mathrm{C}$ than platelets from sodium citrate-anticoagulated blood. Incubation for at least 15 minutes of $20^{\circ} \mathrm{C}$-activated platelets from either anticoagulant restored the discoid morphology of the platelets.

Even after prolonged exposure to $20^{\circ} \mathrm{C}$, the morphological changes of platelets in PRP were generally reversible when the samples were incubated at $37^{\circ} \mathrm{C}$ for 15 minutes. This is demonstrated in Figure 2, which shows a series of phase contrast micrographs of platelets incubated at $20^{\circ} \mathrm{C}$ for increasing periods of time. Aliquots of PRP were removed and fixed after 10 minutes (A), 30 minutes (B), 60 minutes (C), 3 hours (D), and 6 hours $(E)$ at $20^{\circ} \mathrm{C}$. At the same time-points, aliquots were also placed in the $37^{\circ} \mathrm{C}$ water bath and 


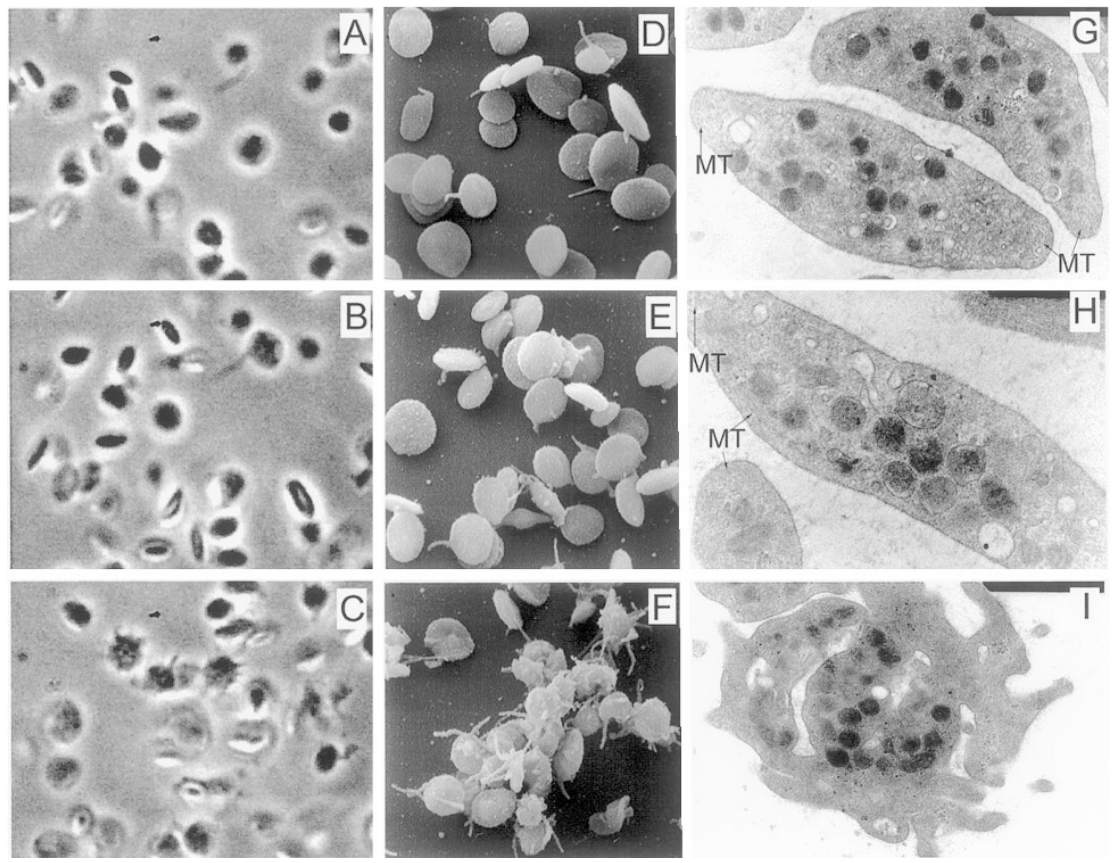

Figure 1.

Temperature-induced activation of platelets: Phase contrast and electron microscopy. The first column (A to C) shows phase contrast micrographs of live platelets The second and third depict scanning electron micrographs ( $D$ to $F)$ and transmission electron micrographs (G to I), respectively. Discoid platelets can be seen at $42^{\circ} \mathrm{C}(\mathrm{A}, \mathrm{D}, \mathrm{G})$ and $37^{\circ} \mathrm{C}(\mathrm{B}, \mathrm{E}, \mathrm{H})$, and morphologically changed platelets at $20^{\circ} \mathrm{C}(\mathrm{C}, \mathrm{F}, \mathrm{I})$. The original magnification for the scanning electron micrographs was $\times 5000$. Microtubules (MT) supporting the discoid form of platelets can be seen in the transmission electron micrographs of platelets at $42^{\circ} \mathrm{C}(\mathrm{G})$ and $37^{\circ} \mathrm{C}(\mathrm{H})$. Original magnifications: $\times 20,000(\mathrm{G}), \times 30,000(\mathrm{H})$, and $\times 20,000(\mathrm{I})$.

incubated for 15 minutes before fixation. The second column of Figure 2 shows the corresponding images of platelets that have recovered their discoid morphology at $37^{\circ} \mathrm{C}$ ( $\mathrm{F}$ to J). Because of sample heterogeneity, a small number of platelets in the whole population did not recover. This number seemed to increase slightly with increasing exposure to low temperature. It is, however, interesting that even after an extended exposure to low temperature, the majority of platelets was able to regain their discoid morphology.

\section{Temperature-Induced Activation of Platelets: Static and Dynamic Light Scattering}

The microscopy results were complemented by static and dynamic light scattering experiments. Both are noninvasive techniques and allow quick monitoring of a large ensemble of platelets rather than subjectively selected single platelets. In addition, a large number of samples can be analyzed in a short time, and no special pretreatment or preparation is necessary. With static light scattering, platelet size and shape can be measured. Dynamic light scattering offers a different approach to measuring the platelet size as well as the surface charge density. In this study, static and dynamic light scattering were chosen to independently test the microscopy results and obtain a more quantitative picture of the morphological changes.

The scattering curves of $20^{\circ} \mathrm{C}, 37^{\circ} \mathrm{C}$, and $42^{\circ} \mathrm{C}$ platelets are shown in Figure $3 \mathrm{~A}$. The scattering curves arise from the angle-dependent scattering intensities of the scattering particles and contain the information on the size and shape of the particles. Most of the light is scattered in the forward direction because platelets are large particles relative to the wavelength of the laser. Differences between the scattering curves from platelets kept at $37^{\circ} \mathrm{C}$ compared with those from platelets incubated at $20^{\circ} \mathrm{C}$ for 10 minutes are only seen at scattering angles less than $45^{\circ}$. The scattering curves for $37^{\circ} \mathrm{C}$ and $42^{\circ} \mathrm{C}$ are identical. Fourier transformation of the scattering curves results in the corresponding pair distance distribution functions (PDDF), where the information on the particle size and shape is more obvious (Glatter, 1979). The corresponding PDDFs obtained from the scattering curves of Panel A are depicted in Figure 3B. It can be seen that the average body of room temperature-activated platelets is globular (the PDDF is nearly symmetrical) and smaller compared with its discoid form at $37^{\circ} \mathrm{C}$ and $42^{\circ} \mathrm{C}$. The discoid form is indicated by the asymmetrical form of the PDDF. The longest distance in the PDDF corresponds to the maximum dimension of the scattering particles. The pseudopods do not significantly contribute to the light scattering and thus, to the PDDF because their diameter is small compared with the platelet body (Kerker, 1983). Static light scattering experiments on platelets from three different donors gave similar results.

Figures $3 C$ and $3 D$ show the volume-weighted size distributions (C) and the electrophoretic mobilities (D) calculated from dynamic light scattering. The size distributions in Panel $\mathrm{C}$ show the distributions of the hydrodynamic radii $\left(R_{H}\right)$ of the scattering particles, which were calculated from the velocity of the Brown- 

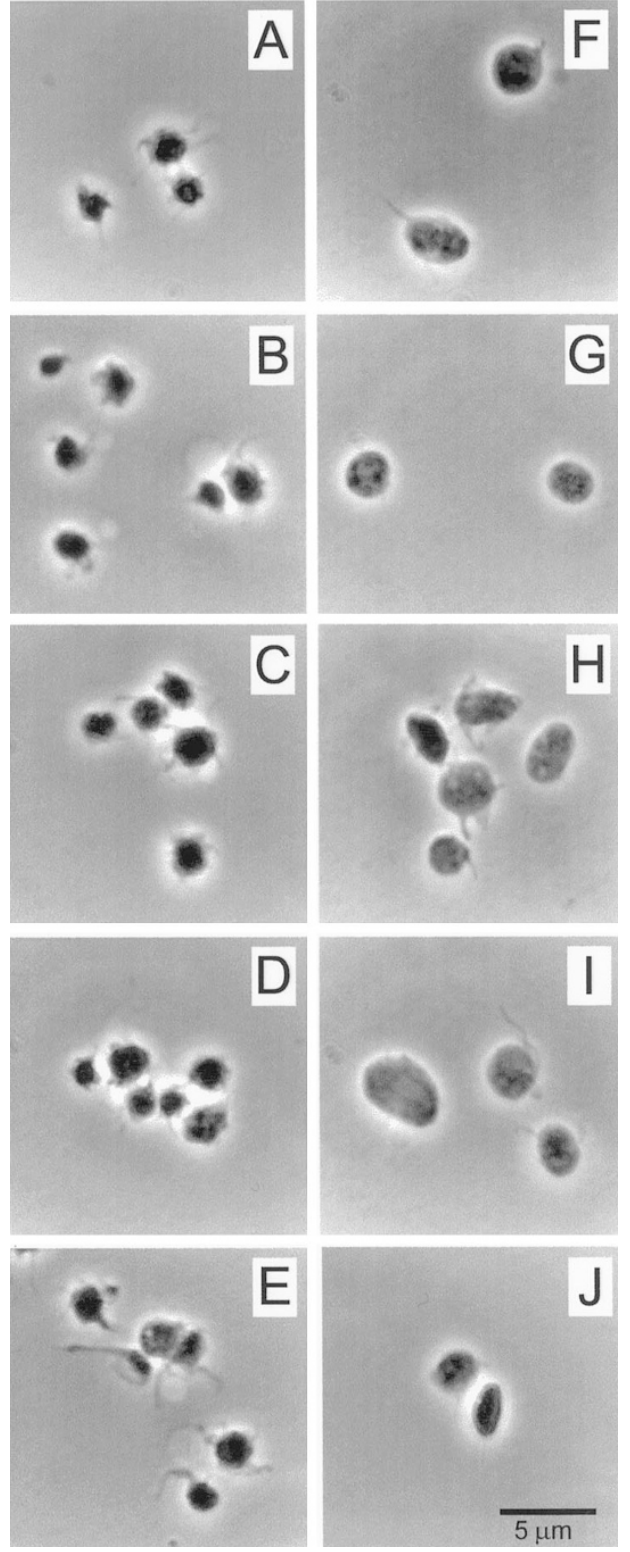

Figure 2.

Reversibility of platelet activation induced by exposure to $20^{\circ} \mathrm{C}$. The first column (A to $E$ ) shows phase contrast micrographs of platelets incubated at $20^{\circ} \mathrm{C}$ for 10 minutes (A), 30 minutes (B), 1 hour (C), 3 hours (D), and 6 hours (E). The second column ( $F$ to $\mathrm{J}$ ) depicts phase contrast micrographs after these samples were incubated at $37^{\circ} \mathrm{C}$ for 15 minutes. All samples were fixed with paraformaldehyde ( $2 \%$ final concentration) for 30 minutes at the appropriate temperature.

ian motion of these scattering particles. The Brownian motion decreases with increasing friction of the particles in solution, which can be caused by an increase in particle volume or a change in particle shape. Activation of platelets at $20^{\circ} \mathrm{C}$ finds expression in a substantial increase in the apparent size. Discoid, resting platelets at $37^{\circ} \mathrm{C}$ and $42^{\circ} \mathrm{C}$ have essentially the same size, indicated by a comparable mean hydrodynamic radius $R_{H}$ (Panel $C$ ). Because $R_{H}$ is calculated from the Brownian motion of the platelets and not the angular scattering intensity, it is not equivalent to the maximum dimension derived from the PDDF.
The electrophoretic mobilities of platelets at $37^{\circ} \mathrm{C}$ and $42^{\circ} \mathrm{C}$ were also very similar whereas they decreased by $40 \%$ for platelets cooled to $20^{\circ} \mathrm{C}$. The value of $-1.7 \times 10^{-8} \mathrm{~m}^{2} \mathrm{~V}^{-1} \mathrm{~s}^{-1}$ for the electrophoretic mobility of platelets at $20^{\circ} \mathrm{C}$ compares well with that in the literature. Gabriel et al (1993) reported an electrophoretic mobility range for platelets at $22^{\circ} \mathrm{C}$ of -1.5 to $-2.0 \times 10^{-8} \mathrm{~m}^{2} \mathrm{~V}^{-1} \mathrm{~s}^{-1}$. Values for the electrophoretic mobility of platelets at $37^{\circ} \mathrm{C}$ have not been published so far. The results from electrophoretic and diffusion light scattering (EDLS) are summarized in Table 1. Together with the microscopy results, it was concluded that the $50 \%$ increase in apparent size and the $40 \%$ decrease in electrophoretic mobility for platelets exposed to $20^{\circ} \mathrm{C}$ were caused by platelet shape change. Human platelets did not change their morphology when PRP was heated to $42^{\circ} \mathrm{C}$ for 20 minutes. This was shown by unaltered electrophoretic mobility and size for platelets at $42^{\circ} \mathrm{C}$ in comparison with resting platelets kept at $37^{\circ} \mathrm{C}$. Changes of platelet morphology were observed at temperatures higher than $42^{\circ} \mathrm{C}$ by both EDLS and scanning electron microscopy (results not shown). The temperaturedependent shape change measurement with dynamic light scattering (from $20^{\circ} \mathrm{C}$ to $37^{\circ} \mathrm{C}$ ) was repeated 70 times because it was also used as the "control" activation for several different studies.

Because the mean $R_{H}$ was found to be a good indicator of the average platelet morphology, it was used to investigate the temperature dependence of platelet activation in more detail. Figure 4 shows the change in $R_{H}$ as a function of the temperature. As the temperature was lowered from $37^{\circ} \mathrm{C}$ to $30^{\circ} \mathrm{C}$, only minor alterations in platelet morphology were observed, indicated by small changes in $R_{H}$. Below $30^{\circ} \mathrm{C}$ the increase in $R_{H}$ with decreasing temperature was more pronounced, suggesting that temperatures below $30^{\circ} \mathrm{C}$ are more effective in stimulating platelet shape change.

\section{Flow Cytometry of Platelets at Different Temperatures}

Flow cytometry is a widely accepted method for the detection of platelet activation (Devine et al, 1999). Activated GPIIb-IIla is expressed on platelets activated by chemical agonists. Elevated levels of the activated form of this integrin are correlated to cytoskeletal rearrangements (Fox et al, 1993), as well as to the initiation of secretory pathways (Hawiger, 1989). To determine whether the morphological changes occurring at room temperature find expression in the biochemistry of the cell, we tested for the appearance of activation markers on the platelet plasma membrane.

Representative histograms from flow cytometry are shown in Figure 5. The first column depicts the light scattering panels (log side scattering vs log forward scattering). The second column shows the amount of FITC-labeled PAC-1 binding or, in the case of the negative control (Fig. 5A), the amount of nonspecific antibody binding, and the third column depicts the amount of phycoerythrin (PE)-labeled anti-CD42b bound to the surface of the platelets. Platelets at $37^{\circ} \mathrm{C}$ 

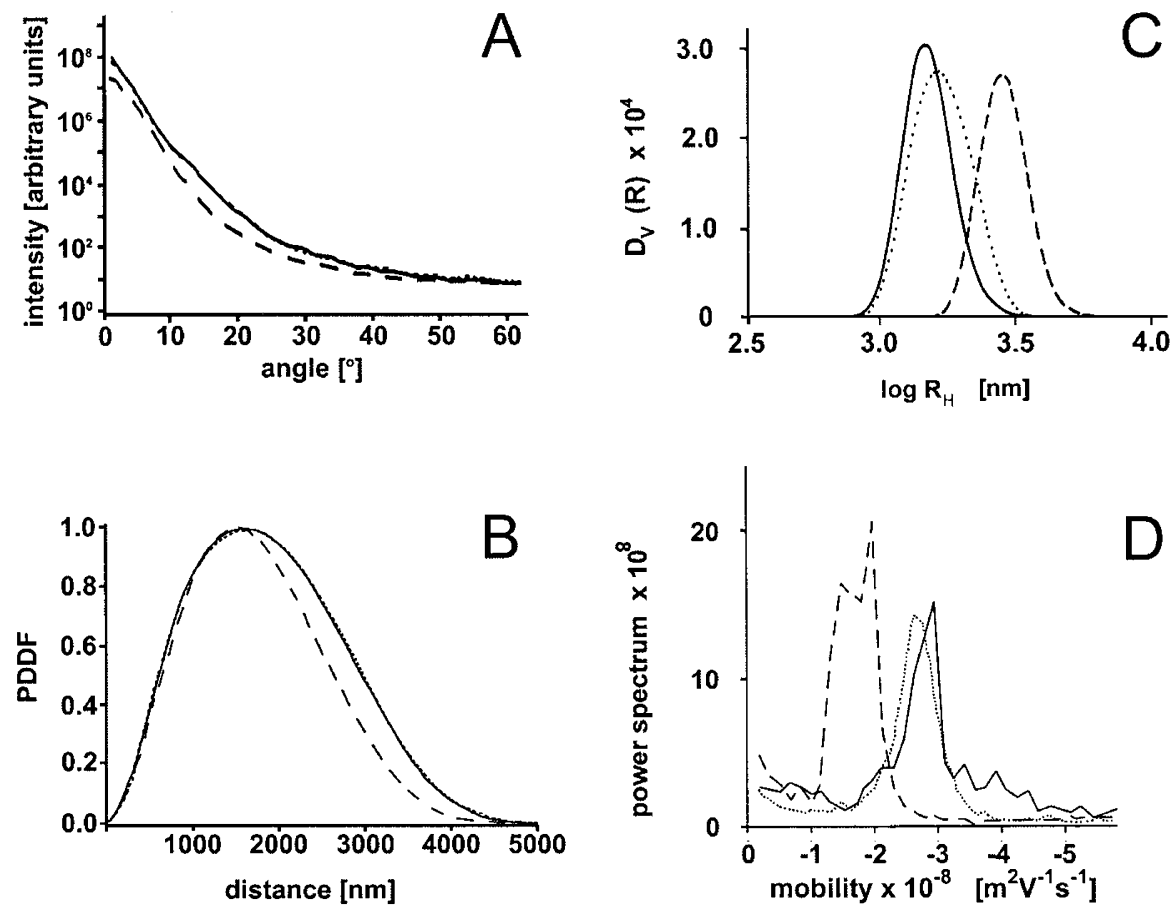

Figure 3.

Temperature induced activation of platelets: static $(A$ and $B)$ and dynamic light scattering $(C$ and $D)$. In all four panels the same line types are used. The signals from platelets at $20^{\circ} \mathrm{C}$ are shown as dashed lines, from platelets at $37^{\circ} \mathrm{C}$ as full lines, and from platelets at $42^{\circ} \mathrm{C}$ as dotted lines. The normalized scattering curves of platelets at $20^{\circ} \mathrm{C}, 37^{\circ} \mathrm{C}$, and $42^{\circ} \mathrm{C}$ are shown in Panel $\mathrm{A}$. The pair distance distribution functions obtained from these scattering curves are shown in Panel $\mathrm{B}$. The symmetry of the pair distance distribution function is indicative of the symmetry of the scattering particles. Spherical particles lead to a very symmetrical pair distance distribution function. The maximal distance denotes the largest dimension inside the scattering particles. Panel $\mathrm{C}$ shows the calculated volume weighted size distributions of platelets at $20^{\circ} \mathrm{C}, 37^{\circ} \mathrm{C}$, and $42^{\circ} \mathrm{C}$. The hydrodynamic radius $\left(\mathrm{R}_{\mathrm{H}}\right)$ is an apparent size parameter calculated from the thermal motion. Increased friction reduces the thermal motion of the particles, which occurs when the scattering particles increase in size or change their shape. The electrophoretic mobilities $(\mu)$ for platelets at the three different temperatures are illustrated in Panel D. The results from dynamic light scattering (C and D) are summarized in Table 1.

Table 1. Summary of EDLS Results ${ }^{a}$

\begin{tabular}{ccccccc}
\hline $\begin{array}{c}\mathrm{T} \\
\left({ }^{\circ} \mathrm{C}\right)\end{array}$ & $\begin{array}{c}\mathrm{D} \\
\left(\mathrm{m}^{2} \mathrm{~s}^{-1}\right) \times 10^{-13}\end{array}$ & $\begin{array}{c}\eta \\
(\mathrm{Pa} \mathrm{s}) \times 10^{-3}\end{array}$ & $\begin{array}{c}\mathrm{R}_{\mathrm{H}} \\
(\mathrm{nm})\end{array}$ & $\epsilon_{\mathrm{r}}$ & $\left(\mathrm{m}^{2} \mathrm{~V}^{-1} \mathrm{~s}^{-1}\right) \times 10^{-8}$ & $(\mathrm{~V}) \times 10^{-3}$ \\
\hline 42 & $1.52 \pm 0.1$ & $1.05 \pm 0.04$ & $1450 \pm 180$ & 73.1 & $-2.71 \pm 0.11$ & $-44 \pm 3$ \\
37 & $1.46 \pm 0.1$ & $1.18 \pm 0.05$ & $1340 \pm 150$ & 74.3 & $-2.63 \pm 0.09$ & $-47 \pm 6$ \\
20 & $0.48 \pm 0.1$ & $1.60 \pm 0.11$ & $2780 \pm 300$ & 80.4 & $-1.70 \pm 0.08$ & $-38 \pm 4$ \\
\hline
\end{tabular}

EDLS, electrophoretic and diffusion light scattering.

${ }^{a}$ The measured parameters are the diffusion coefficient $(D)$ and the electrophoretic mobility $(\mu)$. The diffusion coefficient can be related to the hydrodynamic radius $\left(R_{H}\right)$ according to the Stokes-Einstein equation $\left(D=k T / 6 \pi \eta R_{H}\right.$, where $k$ is the Boltzmann constant, T the absolute temperature, and $\eta$ the viscosity of the solution. Smoluchowski's equation relates the electrophoretic mobility $(\mu)$ to the zeta potential $(\zeta: \mu=\zeta \epsilon / \eta)$. The relative dielectric constant is given as $\epsilon=\epsilon_{\mathrm{r}} \times 8.859 \mathrm{E}-12$ $\mathrm{Fm}^{-1}$.

or $42^{\circ} \mathrm{C}$ showed a wide scattering plot characteristic for resting platelets, as well as no PAC-1 binding and full accessibility of CD42b (Fig. 5B). The analogous panels in Figure $5 \mathrm{C}$ show the results for platelets activated at $20^{\circ} \mathrm{C}$. The scatter plot is narrow, because of granule centralization, and PAC-1 binding was increased. Both features were even more pronounced after platelets were activated with $1 \mathrm{lU} / \mathrm{mL}$ thrombin in the presence of the tetrapeptide Gly-Pro-Arg-Pro (GPRP) (Fig. 5D).

As a summary of the flow cytometry results, Figure 6 shows the binding of the FITC-labeled antibodies PAC-1, antifibrinogen, and anti-CD63, as well as the PE-labeled anti-CD62P to platelets in PRP incubated for 10 minutes at $20^{\circ} \mathrm{C}, 37^{\circ} \mathrm{C}$, and $42^{\circ} \mathrm{C}$. Platelets incubated at $20^{\circ} \mathrm{C}$ showed a marked increase in activated GPIIb-IIla expression, with PAC-1 binding to $25 \%$ to $30 \%$ of the platelet population. Correlating with the improved morphology of platelets isolated from ACD-anticoagulated blood, we also saw only half the PAC-1 binding to these platelets compared with platelets isolated from citrate-anticoagulated blood (data not shown). The amount of fibrinogen bound to the platelet surface was also elevated compared with $37^{\circ} \mathrm{C}$ platelets (Fig. 6). In the presence of fluoxetine, a serotonin re-uptake inhibitor, some expression of the lysosomal/dense granule marker CD63 could be detected on the surface of discoid platelets at $37^{\circ} \mathrm{C}$ and $42^{\circ} \mathrm{C}$. This was in contrast to platelets activated by exposure to $20^{\circ} \mathrm{C}$, which did not express CD63. The 


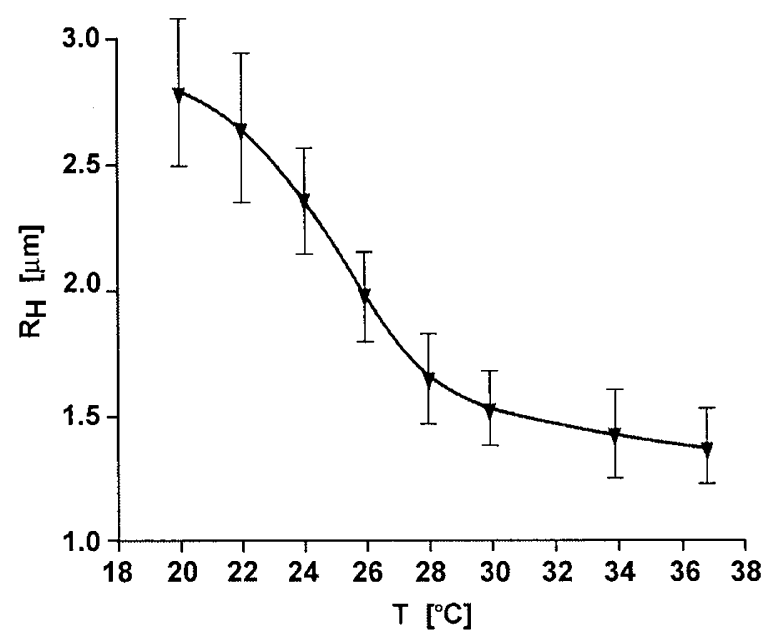

Figure 4.

Nonlinear course of temperature-induced platelet activation. Figure 4 shows the change of the mean hydrodynamic radius $R_{H}$ as a function of temperature. $R_{H}$ is calculated from the results of dynamic light scattering measurements and is a parameter indicative for the average platelet morphology. Minor changes occur between $37^{\circ} \mathrm{C}$ and $30^{\circ} \mathrm{C}$, whereas the $R_{H}$ increases significantly when the platelets are cooled below $30^{\circ} \mathrm{C}$. $\mathrm{R}_{\mathrm{H}}$ increases because activated platelets extend numerous pseudopodia that decrease their Brownian motion (for details see Appendix).

PE-labeled anti-CD62P antibody did not bind to platelets at any of the different incubation temperatures, indicating that there was no $\alpha$-granule release. All platelet samples were inspected routinely by phase contrast microscopy.

\section{Serotonin Concentration in Platelets and Plasma}

The flow cytometry data indicated no release of $\alpha$-granule contents. CD63 is a membrane protein of platelet-dense granules (Nishibori et al, 1993) and is expressed on the platelet surface after dense granule release. Platelet-dense granules are the storage compartments for circulating serotonin. Because differences in CD63 expression levels were found on the plasma membrane of $20^{\circ} \mathrm{C}$ and $37^{\circ} \mathrm{C}$ platelets, we also tested for a temperature-dependent release of serotonin. Serotonin (5-HT) concentrations were measured in the platelet pellet and in plasma. In the presence of serotonin re-uptake inhibitors such as imipramine or fluoxetine, the intracellular 5-HT concentration at $20^{\circ} \mathrm{C}$ was twice as high as at $37^{\circ} \mathrm{C}$ (Fig. 7A). In addition, the plasma 5-HT concentrations were inversely related to the platelet pellet concentrations. The higher $5-\mathrm{HT}$ level in platelets at $20^{\circ} \mathrm{C}$ parallels the reduced expression of CD63 on the surface of these platelets (Figure 6). Serotonin was visualized in platelets after fixation using a monoclonal mouse-antihuman serotonin primary antibody in conjunction with a Texas Red-labeled goat-anti-mouse $F\left(a b^{\prime}\right)_{2}$ secondary antibody. Phase contrast and fluorescence micrographs show a representative discoid platelet at $37^{\circ} \mathrm{C}$ (Fig. 7B, a and b) and a platelet after shape change induced by exposure to $20^{\circ} \mathrm{C}$ for 10 minutes (Fig. 7B, $C$ and d). Serotonin-containing dense granules appear as bright spots. The relatively high background seen
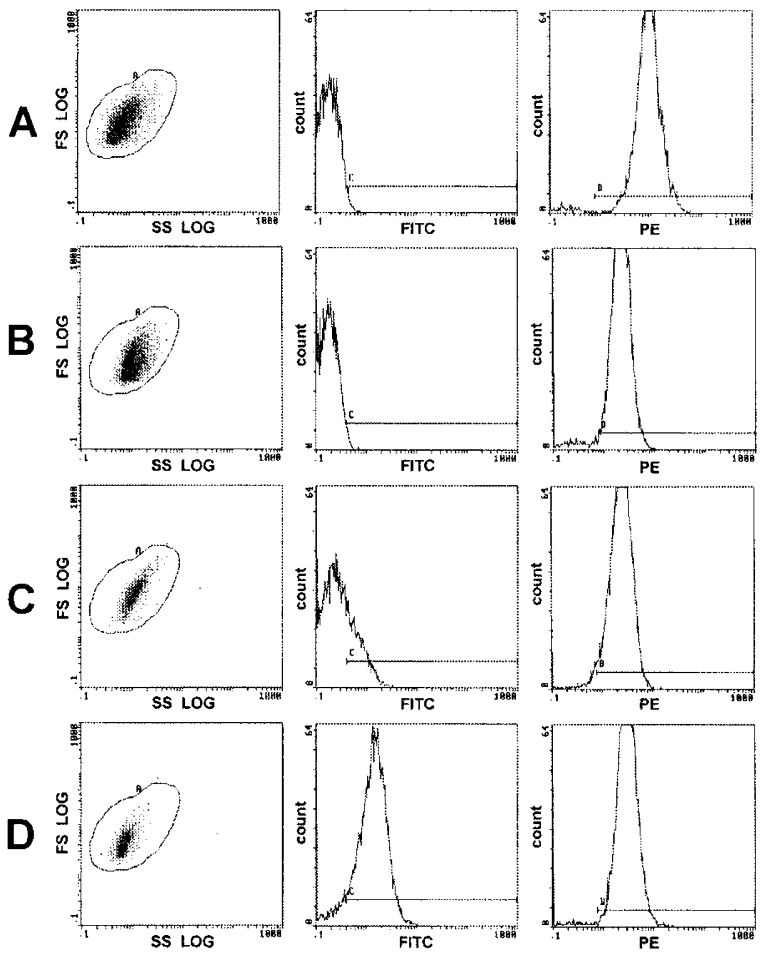

Figure 5 .

Flow cytometry results of platelets at different temperatures. Figure 5 shows the scatter plots (log side scattering vs log forward scattering) and two fluorescence histograms (FITC and phycoerythrin [PE] fluorescence vs platelet count) indicative for binding of FITC-labeled PAC-1 antibodies to activated glycoprotein (GP) IIb-IIla and PE-labeled anti-CD42b binding to the glycoprotein (GP) Ib-IX-V complex on platelets in platelet-rich plasma (PRP). The four rows show the results for nonspecific antibodies (negative control, A), resting platelets at $37^{\circ} \mathrm{C}$ or $42^{\circ} \mathrm{C}(\mathrm{B})$, activated platelets incubated at $20^{\circ} \mathrm{C}$ for 10 minutes $(C)$, and for platelets activated with $1 \mathrm{IU} / \mathrm{mL}$ thrombin in the presence of GPRP (positive control, D).

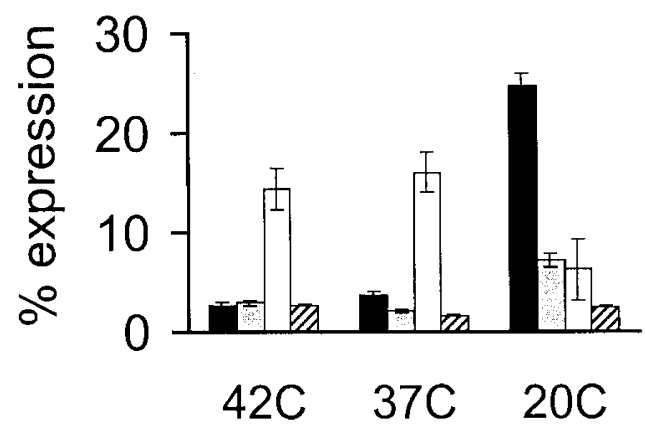

Figure 6.

Flow cytometry of platelets at different temperatures. Figure 6 shows the binding of FITC-labeled antibodies PAC-1 (black bars), antifibrinogen (gray bars), and anti-CD63 (white bars) and the PE-labeled anti-CD62P (striped bars) to platelets in PRP at the indicated temperature measured with flow cytometry. Platelets were activated with $1 \mathrm{lU} / \mathrm{ml}$ thrombin for positive control and binding of a nonspecific antibody was the negative control.

with fluorescence microscopy is due to the use of secondary antibody staining. Control samples of platelets, where the 5-HT specific antibody was omitted or of cells that lack intracellular 5-HT such as leukocytes, showed only background fluorescence (data not shown). Visual comparison of the staining 


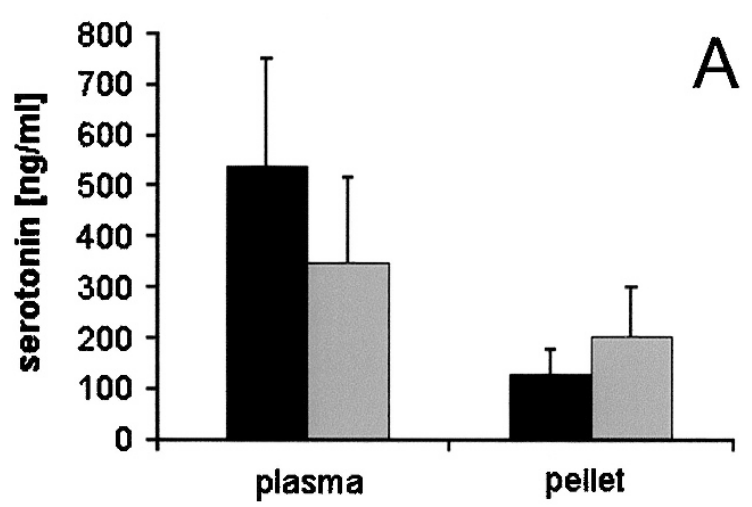

B
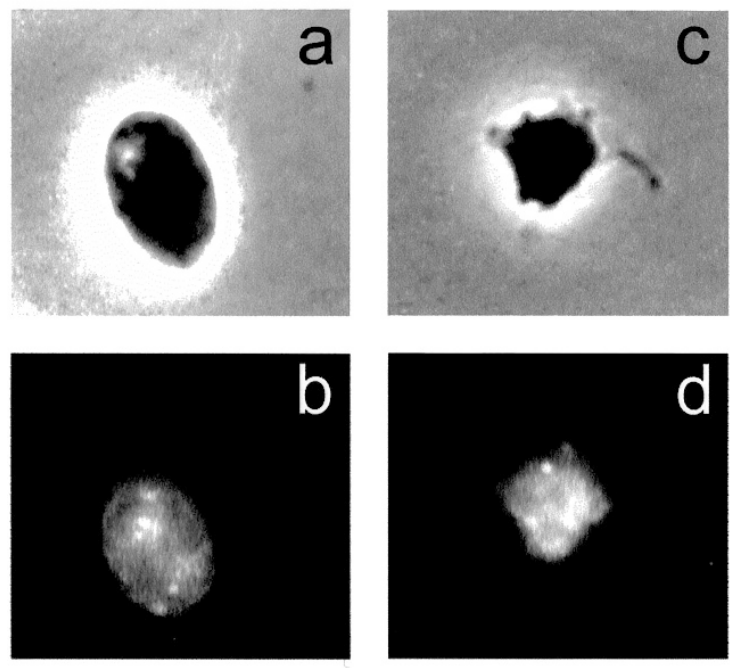

Figure 7.

Serotonin concentration in platelets and plasma. A, The average serotonin concentrations in plasma and the platelet pellet from three healthy donors at $37^{\circ} \mathrm{C}$ (black bars) and at $20^{\circ} \mathrm{C}$ (gray bars) in the presence of 5-hydroxytryptamine, serotonin (5-HT) re-uptake inhibitors, such as imipramine or fluoxetine are shown. An ELISA kit was used for the determination of plasma $5-\mathrm{HT}$, whereas the concentrations in the pellet were measured by high pressure liquid chromatography/absorbance detection. B, Histochemical detection of $5-\mathrm{HT}$ in platelet-dense granules. Phase contrast and fluorescence micrographs show a discoid platelet at $37^{\circ} \mathrm{C}$ ( $\mathrm{a}$ and $\mathrm{b}$ ) and a platelet after temperature-induced shape change at $20^{\circ} \mathrm{C}(\mathrm{C}$ and d). Serotonin is indicated by bright dots in the fluorescence micrographs caused by a secondary Texas Red-labeled antibody to a serotonin antibody.

intensities supports the data obtained with HPLC/ ELISA and flow cytometry.

\section{Discussion}

This is the first report comparing the effects of hypothermia and the consequences of heat shock on platelets to a platelet population kept at $37^{\circ} \mathrm{C}$. Platelet morphology, integrin activation and granule release were investigated. Platelets cooled to $20^{\circ} \mathrm{C}$ showed marked changes in morphology, ultrastructure, membrane protein expression, and serotonin content compared with resting platelets at $37^{\circ} \mathrm{C}$. Moderate heat shock conditions $\left(42^{\circ} \mathrm{C}\right)$ did not induce any changes in all these parameters.

With dynamic light scattering, we showed that platelet morphology does not steadily change with decreasing temperature from $37^{\circ} \mathrm{C}$ to $20^{\circ} \mathrm{C}$. Subtle changes occurred between $30^{\circ} \mathrm{C}$ to $37^{\circ} \mathrm{C}$, whereas cooling below $30^{\circ} \mathrm{C}$ caused significant platelet activation. At $20^{\circ} \mathrm{C}$ the majority of platelets were activated to spherical cells with pseudopods.

The finding that room temperature activates platelets seems to be contradictory to other reports that showed that platelets prepared at room temperature maintain discoid morphology (Patscheke and Wörner, 1978). However, it has to be taken into account that discoid platelet morphology in many studies was preserved by low pH (Mustard et al, 1989; Nachmias et al, 1987; Patscheke, 1981). Our own results confirmed the inhibitory effect of a low $\mathrm{pH}$ anticoagulant such as ACD on both the morphological changes and the expression of activated GPIllb-IIla. The mechanism that leads to the inhibition of platelet activation at low $\mathrm{pH}$ is not known. Discoid morphology can also be restored during a resting period of at least 15 minutes at $37^{\circ} \mathrm{C}$ after preparation of PRP at $22^{\circ} \mathrm{C}$ to $24^{\circ} \mathrm{C}$ (Gear, 1984; Winokur and Hartwig, 1995; Zucker and Borrelli, 1954). We were able to show that, even after 6 hours at $20^{\circ} \mathrm{C}$, the morphological signs of platelet activation were reversible. Therefore, platelet researchers conducting in vitro studies generally consider room temperature not harmful for platelets. In the context of platelet research, hypothermia is classified as the exposure of platelets to $4^{\circ} \mathrm{C}$ during chilling and refrigeration. The literature on chilled platelets unequivocally reports activation of platelets with severe morphological changes.

The clinical classification of hypothermia is substantially different from the classification used for platelet in vitro studies (Kirkpatrick et al, 1999). A body temperature between $35^{\circ} \mathrm{C}$ and $32^{\circ} \mathrm{C}$ is classified as mild, between $32^{\circ} \mathrm{C}$ and $28^{\circ} \mathrm{C}$ as moderate, and below $28^{\circ} \mathrm{C}$ as severe hypothermia, which is lethal in most cases. During surgery such as cardiopulmonary bypass, the patient or parts of the patient's body and the blood in the extracorporeal circulation are cooled to temperatures between $37^{\circ} \mathrm{C}$ and $20^{\circ} \mathrm{C}$ (Boldt et al, 1996). As a consequence of hypothermia, hemostatic dysfunction was observed (Boldt et al, 1996; Michelson et al, 1999). The reason for the hemostatic failure is unknown, but platelet dysfunction was suggested to play a major role. The literature on chilled platelets is often cited in connection with the clinical effects of hypothermia; however, $4^{\circ} \mathrm{C}$ is clearly a much lower temperature than reached in clinical situations.

With the appreciation of this discrepancy, a new body of literature has emerged that is concerned with the effect of room temperature on platelets. However, controversial results are reported. Reduced platelet function induced by hypothermia in the forearm of the blood donor was measured by prolonged bleeding time. No effect on platelet P-selectin and thromboxane $B_{2}$ levels was reported (Michelson et al, 1999). Our findings that $\alpha$-granules are not involved in platelet 
activation at room temperature are consistent with these results. However, Michelson et al did not report on platelet morphology, GPIIb-Illa activation, or serotonin, parameters that we found to change at low temperature. Increased reactivity of platelets at $22^{\circ} \mathrm{C}$ to ADP and collagen has been reported as well (Faraday and Rosenfeld, 1998). It is interesting to note that platelet isolation from whole blood by these researchers was carried out at room temperature. This might explain why Faraday and Rosenfeld did not see differences in fibrinogen binding and only a very small difference of PAC-1 binding of platelets at $37^{\circ} \mathrm{C}$ and $22^{\circ} \mathrm{C}$, unless ADP was added.

Hypothermia was reported to result in a marked prolongation of the bleeding time (Michelson et al, 1994, 1999). A prolonged bleeding time is also one of the primary symptoms of patients with serotonin deficiencies (McNicol and Israels, 1999). Platelets transport at least $95 \%$ of the circulating serotonin (Hardisty and Stacey, 1955; Pletscher et al, 1971). Serotonin has an important vasoactive role for wound closure during acute vessel wall injury (Vanhoutte, 1981). We have shown that, in the presence of a serotonin re-uptake inhibitor, the temperature-dependent activation of platelets is accompanied by changes in the dense granule content of serotonin directly measured by HPLC and 5-HT ELISA. Our results suggested that, under hypothermic conditions, more serotonin is stored in the platelets and, therefore, less serotonin is available in the plasma. This could have an effect similar to serotonin deficiency, in that the serotonin is not available to exert its contracting effect on the smooth muscle cells and help with wound closure. We hypothesize that this may contribute to the increased bleeding time following hypothermia despite the fact that platelets are activated under these conditions. Activated platelets are considered to enhance coagulation, which would not cause the observed coagulopathy. Activated platelets might, however, also be cleared more rapidly or adhere to foreign surfaces.

We suggest the following model that links the morphological changes to the changes in serotonin content during platelet temperature activation. It is well documented in the literature that platelets circulate as discoid cells (Allen et al, 1979; Bizzozero, 1865; White and Krivit, 1967; Winokur and Hartwig, 1995). We hypothesize that the temperature-dependent shape change is initiated by temperature-induced changes within the plasma membrane. Both phospholipid asymmetry (Zwaal et al, 1998) and the fluidity of the plasma membrane are highly affected by temperature (Cossins, 1994; Tablin et al, 1996). Membrane asymmetry and fluidity determine the conformation and activity of the integrins (Haas et al, 1999), which are anchored to the cytoskeleton of the cell (Fox, 1993; Hagmann et al, 1998). Therefore, it is reasonable to speculate that even local changes in plasma membrane polarization will cause outside-in signaling through conformational changes of integrins and subsequent changes of the integrin/cytoskeleton interaction. Cytoskeletal rearrangements involve many intracellular processes such as mobilization of internal
$\mathrm{Ca}^{2+}$ via phospholipase C (PLC). 5-HT uptake and release are known to correlate with PLC activity, as well as with $\left[\mathrm{Ca}^{2+}\right]_{i}$ fluxes (Martin, 1997). We suggest that the temperature-dependent shape change starts at the level of the plasma membrane. These changes in the plasma membrane lead to changes in the cytoskeleton and the platelet serotonin content through intracellular signals.

This process differs from chemical activation through agonists like ADP or thrombin in that the particular receptors for these agonists are not involved and $\alpha$-granule release is not initiated. Because this process is reversible, it might be interesting to speculate that platelets have an as yet unknown function in signaling temperature changes.

\section{Materials and Methods \\ Preparation of Platelet Rich Plasma}

In all experiments we used human PRP collected from volunteers who had provided informed consent. PRP was prepared at $37^{\circ} \mathrm{C}$. Briefly, 9 volumes of blood were drawn into a prewarmed tube containing 1 volume of sodium citrate (3.8\% final concentration). The blood was kept warm and centrifuged at $150 \times g$ for 12 minutes at $37^{\circ} \mathrm{C}$. PRP was removed with a prewarmed transfer pipette and kept in a $37^{\circ} \mathrm{C}$ water bath for 30 minutes before use. For the investigation of low-temperature activation, part of the recovered PRP was incubated in a water bath controlled at $20^{\circ} \mathrm{C}$ for 10 minutes before the addition of antibodies or fixation at the same temperature.

\section{Fluorescence and Phase Contrast Microscopy}

Live cell microscopy was performed on a Nikon Labophot 2 microscope (Nikon, Tokyo, Japan) using a $100 \times / 1.3$ NA oil immersion objective. The microscope was fitted with a laboratory-built temperature stage and a digital camera (Pixera, Los Gatos, California) for real-time imaging. All glass surfaces were siliconized with dichloro-dimethylsilane (Sigma, St. Louis, Missouri) to avoid adhesion and spreading of live platelets on the glass slides (Fisher Scientific, Pittsburgh, Pennsylvania).

\section{Scanning and Transmission Electron Microscopy}

Scanning electron microscopy was performed using a Zeiss DSM 950 scanning electron microscope (Zeiss, Jena, Germany). The platelets were prepared as follows: platelets were fixed in 3\% glutaraldehyde in PBS (50 mm NaH $\mathrm{PO}_{4} \cdot \mathrm{H}_{2} \mathrm{O}, 5 \mathrm{~mm} \mathrm{KCl}, 1.5 \mathrm{~mm} \mathrm{MgCl}_{2} \cdot 6 \mathrm{H}_{2} \mathrm{O}$, $80.1 \mathrm{~mm} \mathrm{NaCl}$; pH 7.2) by mixing $400 \mu \mathrm{l}$ of PRP with 1 $\mathrm{ml}$ of glutaraldehyde/buffer solution for 30 minutes at the appropriate temperature. Then platelets were washed with PBS and postfixed for 30 minutes in $2 \%$ $\mathrm{OsO}_{4}$ in $\mathrm{PBS}$ at room temperature. The platelets were centrifuged at $1500 \times g$ for 5 minutes and resuspended in PBS, mixed with $2 \%$ agarose solution, and then dehydrated in a series of ascending ethanol concentrations. After critical-point drying, the samples 
were sputter-coated with gold and zirconium and examined. For transmission electron microscopy, ethanol in the dehydrated sample was exchanged for propylene oxide, and the specimen was embedded in Epon 812 according to Luft (Luft, 1961).

\section{Static and Dynamic Light Scattering}

Static light scattering experiments were carried out on the Flat Cell Light Scattering Instrument as described by Lehner et al (1998). A diode array allows for accumulation of complete scattering curves in an angular range from $1^{\circ}$ to $60^{\circ}$ within short periods of time. In addition, the thickness of the sample compartment can be adjusted to eliminate/reduce multiple scattering. PRP at the appropriate temperature was fixed with $4 \%$ paraformaldehyde 1:1 (v/v) for $30 \mathrm{~min}-$ utes. Without further dilution these samples were analyzed in a $133-\mu \mathrm{m}$-wide flat glass cell at $20^{\circ} \mathrm{C}$. The pair distance distribution functions were calculated from the scattering curves after subtraction of the solvent and blank scattering by indirect Fourier transformation (Glatter, 1977).

Dynamic light-scattering experiments were performed on live platelets in PRP. A laboratory-built light-scattering instrument was used, which allowed for quasi-simultaneous measurement of two independent parameters, electrophoretic mobility, and diffusion coefficient. A detailed description of the instrument can be found in previous publications (Fuchs et al, 1989; Spurej et al, 1992). Size distributions were obtained through Laplace inversion of the measured correlation functions (Glatter et al, 1991; Schnablegger and Glatter, 1991). The plasma viscosity was measured with an oscillating capillary rheometer (OCR, Paar, Austria) or a Cannon A412 viscometer (Cannon Instruments, State College, Pennsylvania) at $20^{\circ} \mathrm{C}, 37^{\circ} \mathrm{C}$, and $42^{\circ} \mathrm{C}$. The respective viscosities are listed in Table 1. Electro-osmosis was eliminated by coating of the glass surfaces that would come into contact with the samples with dichloro-dimethylsilane (Sigma). The measured velocity profiles were flat, and thus, it was not necessary to determine the stationary layer. The electrophoretic mobility was measured in the middle of the electrophoresis chamber.

Although static and dynamic light scattering exploit the same phenomenon, the scattering of light by particles, the two techniques are fundamentally different (Ford, 1985; Gabriel et al, 1993). Dynamic light scattering has not been widely used in platelet research. Therefore, we have included as an appendix a brief description of dynamic light scattering, which also discusses how it is different from static light scattering (Fratantoni et al, 1984; Frojmovic and Wong, 1990; Patscheke et al 1984).

\section{Serotonin Measurements}

Plasma levels of serotonin (5-HT) were determined with an ELISA kit (IBL, Darmstadt, Germany) according to the manufacturer's protocol. Serotonin concentrations in the platelet pellet were measured by HPLC using a LiChrosphere reverse-phase column (Merck,
Darmstadt, Germany) in conjunction with an absorbance detector (L-6210 pump and L4200 detector; Merck-Hitachi, Darmstadt, Germany). Samples for HPLC were prepared in the following way. PRP was prepared at $37^{\circ} \mathrm{C}$ as described above. Platelets were counted on a Coulter Counter (Beckman Coulter, Burlington, Ontario) to be able to normalize the results. To protect 5-HT from oxidation, L-cysteine hydrochloride (Fisher Scientific, Fair Lawn, New Jersey) at a final concentration of $5 \mathrm{mg} / \mathrm{ml}$ was added to all samples before the addition of perchloric acid (PCA, $0.2 \mathrm{~N}$ final concentration). For determination of total serotonin in whole blood, the PRP samples were sonicated for 10 seconds and centrifuged for 10 minutes at 12,000 $\times g$ in an Eppendorf centrifuge (Eppendorf, Hamburg, Germany). The supernatant was frozen immediately in liquid nitrogen and kept at $-80^{\circ} \mathrm{C}$ until analyzed. For the separate determinations of plasma and platelet serotonin at $37^{\circ} \mathrm{C}$ and $20^{\circ} \mathrm{C}, 2 \mathrm{mM} \mathrm{CaCl}_{2}$ and $1 \mu \mathrm{M}$ fluoxetine hydrochloride (Sigma) were added to freshly prepared PRP. This was followed by incubation at the appropriate temperature for 30 minutes. The plasma and platelets were separated by centrifugation at 1000 $\times g$ for 15 minutes, and the platelet pellet was resuspended in $200 \mu \mathrm{l}$ PBS. From both the platelet and the plasma fractions, proteins were precipitated with perchloric acid in the presence of cysteine. The samples were centrifuged and the supernatants frozen. Isocratic flow at $1 \mathrm{ml} /$ minutes was used with a mobile phase consisting of $30 \%$ acetonitrile and $70 \%$ phosphate buffer (100 mm NaH $\mathrm{PO}_{4}, 1 \mathrm{~g} / \mathrm{l} \mathrm{SDS,} 0.5 \mathrm{~mm}$ EDTA, pH 4.5). Standards for 5-HT were prepared by dissolving different concentrations of serotonin hydrochloride (Sigma) in water. The standards were treated with cysteine and PCA analogous to the samples. Under these conditions the retention time for serotonin was $3.58 \pm 0.3$ minutes at room temperature, and there was no interference from other substances. The detector wavelength was set to $276 \mathrm{~nm}$. With this HPLC system, the detection limit for $5-\mathrm{HT}$ was 50 $\mathrm{ng} / \mathrm{mL}$, whereas the ELISA can measure serotonin concentrations down to $0.03 \mathrm{ng} / \mathrm{mL}$.

For the histochemical detection of serotonin containing dense granules, PRP was fixed 1:1 (v/v) with 4\% paraformaldehyde in PBS and the platelets subsequently permeabilized by the addition of Triton $\mathrm{X}-100$ in water to a final concentration of $0.2 \%$. The platelets were washed with a HEPES buffer (150 mM $\mathrm{NaCl}, 5 \mu \mathrm{M} \mathrm{KCl,} 1$ mm MgSO ${ }_{4}, 10 \mathrm{~mm}$ HEPES-sodium salt, $\mathrm{pH} 7.4$ ) containing $3 \%$ BSA before a monoclonal mouse-anti-human serotonin antibody (Dako Diagnostics, Mississauga, Ontario) was added. After a brief incubation and another washing step, a secondary Texas Red-labeled goat-anti-mouse $F\left(a b^{\prime}\right)_{2}$ fragment (Jackson Immuno Research, Mississauga, Ontario) was added. Fluorescence microscopy was performed using the microscope setup described above.

\section{Flow Cytometry}

PRP was prepared at $37^{\circ} \mathrm{C}$ and incubated for 30 minutes at this temperature. The antibodies PE- 
labeled anti-CD42b and FITC-labeled anti-CD41 were used as platelet markers, whereas PE-labeled antiCD62P, FITC-labeled anti-CD63, and FITC-labeled PAC-1 were used as activation markers. Antibodies were purchased from Immunotech (Westbrook, Maine), except for FITC-labeled PAC-1 (Becton Dickinson, Mississauga, Ontario) and FITC-labeled antifibrinogen (Dako Diagnostics). Labeled antibodies in HEPES (total volume of $45 \mu \mathrm{l}$ ) were incubated at $20^{\circ} \mathrm{C}, 37^{\circ} \mathrm{C}$, or $42^{\circ} \mathrm{C}$, followed by addition of $5 \mu \mathrm{l}$ PRP. The platelets were allowed to react with the antibodies for 30 minutes at the appropriate temperature. For fixation, $950 \mu \mathrm{l}$ of $0.2 \%$ formaldehyde in normal saline was added. Samples were measured on a Coulter EPICS XL flow cytometer (Miami, Florida). The fluorescence resulting from the binding of a nonspecific antibody was set as $2 \%$ expression (negative control). As a positive control, platelets were activated with $1 \mathrm{lU} / \mathrm{ml}$ thrombin in the presence of $1 \mathrm{~mm}$ of the peptide GPRP (Calbiochem, San Diego, California). Following thrombin activation, binding of the activation marker reached values of $87 \%$ to $99 \%$.

\section{Appendix}

Dynamic light scattering is conceptually similar to a radar velocity measurement. The light scattered by particles is frequency-shifted (Doppler shift) because of the particles' movement relative to a detector positioned at a fixed scattering angle. The random movement of particles is caused by thermal motion (diffusion light scattering). When an electric field is applied, the movement of the scattering particles is directed (electrophoretic light scattering). For practical reasons it is easier to analyze intensity fluctuations (time domain) rather than measure frequency shifts (frequency domain). Time and frequency domain are Fourier transform pairs, and data can be easily interconverted. In the following paragraphs, the dynamic light scattering arising from the particle movement caused by thermal motion will be discussed.

The fluctuations in scattering intensity originate from the movement of the particles in solution. The smaller and smoother the particles are, the faster they will move in solution, and the faster the intensity fluctuations will be, and vice versa. Thus, the time dependence of the scattering intensity, represented by its correlation function, provides information on the motion of the scattering particle. If all particles are of the same size, the correlation function is a single exponential function. Its decay is governed by the diffusion coefficient. The diffusion coefficient $(D)$ is related through the Stokes-Einstein equation to the hydrodynamic radius $\mathrm{R}_{\mathrm{H}}\left(\mathrm{D}=\mathrm{kT} / 6 \pi \eta \mathrm{R}_{\mathrm{H}}\right.$, where $\mathrm{k}$ is the Boltzmann constant, $\mathrm{T}$ the temperature, and $\eta$ the viscosity). $R_{H}$ corresponds to the size of an equivalent sphere that moves with the same velocity as the particles in solution. Although the volume of platelets does not change substantially upon shape change, the formation of pseudopods increases friction to such an extent that the movement of the platelets is slowed down. Therefore, a platelet with pseudopods moves with the same speed as an equivalent sphere of about double the size of a discoid platelet. For a polydisperse sample, the hydrodynamic radius constitutes an ensemble average. The particle motion in an electric field is essentially proportional to the surface charge density of the particle and is commonly presented in the form of a frequency spectrum. The frequency shift $\Delta \nu$ is related to the electrophoretic mobility $\mu: \Delta \nu=\mu$.E.K, with $\mathrm{E}$ being the electric field strength and $\mathrm{K}$ a constant, depending on the scattering angle and the wavelength of the light source. The electrophoretic mobility can be converted into a zeta potential $(\zeta)$ using the Smoluchowski equation $\mu=$ $\zeta \epsilon / \eta$, where $\epsilon$ is the dielectric constant of the solution and $\eta$ its viscosity.

In static light scattering, time-averaged scattering intensities are measured at a series of different scattering angles in contrast to the short-time fluctuations measured in EDLS at a fixed angle. The angular dependence of the particle interference pattern (scattering curve) contains information about the size and shape of the particles in solution. Particle size (real space) and scattering angle (reciprocal space) are inversely related, and the relationship between the solution structure of the object and its scattering curve can be mathematically described by a Fourier transformation. A direct consequence of this inverse relationship is that particles large in comparison to the wavelength of light (which is the probe), such as platelets, scatter predominantly to small angles (in forward direction). Changes in platelet morphology are therefore expected to manifest themselves in the scattering curves at small scattering angles. The information on particle shape is not immediately obvious from the scattering curves, but it can be obtained without any further assumptions from the pair distance distribution function (PDDF) (Glatter, 1977). The PDDF represents a histogram of distances inside the particle and goes to zero at the maximum particle dimension. It is like a fingerprint pattern for a particular shape, symmetrical for spherical particles and progressively asymmetric for oblate to cylindrical particles.

\section{References}

Allen RD, Zacharski LR, Widirstky ST, Rosenstein R, Zaitlin LM, and Burgess DR (1979). Transformation and motility of human platelets. J Cell Biol 83:127-142.

Bizzozero J (1865). Ueber einen neuen Formbestandtheil des Blutes und dessen Rolle bei der Thrombose und der Blutgerinnung. Archiv Pathol Anat 40:261-331.

Boldt J, Knothe C, Welters I, Dapper FL, and Hempelmann G (1996). Normothermic versus hypothermic cardiopulmonary bypass: Do changes in coagulation differ? Ann Thorac Surg 62:130-135.

Breddin K, Grun H, Ziemen M, Bauer M, and Krzywanek HJ (1975). Factors influencing spontaneous and induced platelet aggregation. Studies with a new aggregometer. In: Ulutin ON, editor. Platelets. Amsterdam: Excerpta Medica, 302-314.

Cossins AR (1994). Homeoviscous adaptation of biological membranes and its functional significance. In: Cossins AR, 
editor. Temperature adaptation of biological membranes. London: Portland Press, 65-76.

Devine DV, Bradley AJ, Maurer E, Levin E, Chahal S, Serrano K, and Gyongyossy-Issa MI (1999). Effects of prestorage white cell reduction on platelet aggregate formation and the activation state of platelets and plasma enzyme systems. Transfusion 39:724-734.

Faraday N and Rosenfeld BA (1998). In vitro hypothermia enhances platelet GPIIb-IIla activation and P-selectin expression. Anesthesiology 88:1579-1585.

Ford NC Jr (1985). Light scattering apparatus. In: Pecora R, editor. Dynamic light scattering: Applications of photon correlation spectroscopy. New York and London: Plenum Press, 7-58.

Fox JEB (1993). The platelet cytoskeleton. Thromb Haemost 70:884-893.

Fox JEB, Lipfert L, Clark EA, Reynolds CC, Austin CD, and Brugge JS (1993). On the role of the platelet membrane skeleton in mediating signal transduction. J Biol Chem 268: 25973-25984.

Fratantoni JC, Poindexter BJ, and Bonner RF (1984). Quantitative assessment of platelet morphology by light scattering: A potential method for the evaluation of platelets for transfusion. J Lab Clin Med 103:620-631.

Frojmovic MM and Wong T (1990). The platelet extinction coefficient measured by aggregometry is dependent on platelet composition rather than size: Implications for studies of platelet heterogeneity and abnormalities. Thromb Haemost 64:582-588.

Fuchs HF, Jorde C, and Glatter O (1989). Interactive data acquisition system for quasi elastic light scattering. Rev Sci Instrum 60:854-857.

Gabriel DA, Reece NS, Li X, Witte JH, and Muga KM (1993). Electrophoretic light scattering studies on the interaction of fibrinogen with resting and activated human platelets. Blood Coag Fibrinol 4:397-403.

Gear ARL (1984). Rapid platelet morphological changes visualized by scanning-electron microscopy: Kinetics derived from a quenched-flow approach. Br J Haematol 56:387-398.

Glatter O (1977). A new method for the evaluation of smallangle scattering data. J Appl Cryst 10:415-421.

Glatter O (1979). The interpretation of real-space information from small-angle scattering experiments. J Appl Crys 12: $166-175$.

Glatter O, Sieberer J, and Schnablegger H (1991). A comparative study on different scattering techniques and data evaluation methods for sizing of colloidal systems using light scattering. Part Syst Charact 8:274-281.

Haas TA, Lyman S, Plow EF, and White GC (1999). Structural analysis of a cytoskeletal binding domain in the $\beta$ subunit of $\alpha_{\text {IIB } \beta 3}$. Thromb Haemost Suppl 1:512.

Hagmann J, Grob M, Welman A, van Walligen G, and Burger MM (1998). Recruitment of the LIM protein hic-5 to focal contacts of human platelets. J Cell Sci 111:2181-2188.

Hardisty RM and Stacey RS (1955). 5-Hydroxytryptamine in normal human platelets. J Physiol 130:711-720.

Hawiger J (1989). Platelet secretory pathways: An overview. Methods Enzymol 169:191-195.
Kerker M (1983). Elastic and inelastic light scattering in flow cytometry. Cytometry 4:1-10.

Kirkpatrick AW, Chun R, Brown R, and Simons RK (1999). Hypothermia and the trauma patient. Can J Surg 42:333-343.

Lehner D, Kellner G, Schnablegger H, and Glatter O (1998). Static light scattering on dense colloidal systems: New instrumentation and experimental results. J Colloid Interface Sci 201:34-47.

Luft JH (1961). Improvements in epoxy resin embedding methods. J Biophys Biochem Cytol 9:409-414.

Martin TFJ (1997). Stages of regulated exocytosis. Trends in Cell Biol 7:271-276.

McNicol A and Israels SJ (1999). Platelet dense granules: Structure, function and implications for haemostasis. Thromb Res 95:1-18.

Michelson AD, Barnard MR, Khuri SF, Rohrer MJ, MacGregor $H$, and Valeri CR (1999). The effect of aspirin and hypothermia on platelet function in vivo. $\mathrm{Br} \mathrm{J}$ Haematol 104:64-68.

Michelson AD, MacGregor H, Barnard MR, Kestin AS, Rohrer MJ, and Valeri CR (1994). Reversible inhibition of human platelet activation by hypothermia in vivo and in vitro. Thromb Haemost 71:633-640.

Milton JG, Hutton RA, Tuddenham EGD, and Frojmovic MM (1985). Platelet size and shape in hereditary giant platelet syndromes on blood smear and in suspension: Evidence for two types of abnormalities. J Lab Clin Med 106:326-335.

Murphy S and Gardner FG (1969). Platelet preservation. Effect of storage temperature on maintenance of platelet viability: Deleterious effect of refrigerated storage. N Engl J Med 280:1094-1098.

Mustard JF, Kinlough-Rathbone RL, and Packham MA (1989). Isolation of human plasma by centrifugation and washing. Methods Enzymol 169:3-11.

Nachmias VT (1980). Cytoskeleton of human platelets at rest and after spreading. J Cell Biol 86:795-802.

Nachmias VT, Yoshida K, and Glennon MC (1987). Lowering $\mathrm{pH}$ in blood platelets dissociates myosin phosphorylation from shape change and myosin association with the cytoskeleton. J Cell Biol 105:1761-1769.

Nishibori M, Cham B, McNicol A, Shaley A, Jain N, and Gerrard JM (1993). The protein CD63 is in platelet dense granules, is deficient in a patient with Hermansky-Pudlak syndrome, and appears identical to granulophysin. J Clin Invest 91:1775-1782.

Pasha R, Benavides M, Kottke-Marchant K, and Harasaki H (1995). Reduced expression of platelet surface glycoprotein receptor Ilb/IIla at hyperthermic temperatures. Lab Invest 73:403-408.

Patscheke $\mathrm{H}$ (1981). Shape and functional properties of human platelets washed with acid citrate. Haemostasis 10:14-27.

Patscheke H, Dubler D, Deranleau D, and Lüscher EF (1984). Optical shape change analysis in stirred and unstirred human platelet suspensions. A comparison of aggregometric and stopped-flow turbidimetric measurements. Thromb Res 33: 341-353.

Patscheke H and Wörner P (1978). Platelet activation detected by turbidimetric shape-change analysis. Differential influence of cytochalasin $B$ and prostaglandin $E_{1}$. Thromb Res 12:485-496. 
Pereira Arias AM, Wester JP, Blankendaal M, Schilthuis MS, Kuijper EJ, Rademaker BM, Stoutenbeek CP, and Rietbroek RC (1999). Multiple organ function syndrome induced by whole body hyperthermia and polychemotherapy in a patient with disseminated leiomyosarcoma of the uterus. Intensive Care Med 25:1013-1016.

Pletscher A, Da Prada M, Berneis KH, and Tranzer JP (1971). New aspects of the storage of 5-hydroxytryptamine in blood platelets. Experientia 27:993-1120.

Rao GHR, Smith II CM, Escolar G, and White JG (1993). Influence of heat on platelet biochemistry, structure, and function. J Lab Clin Med 122:455-464.

Schnablegger H and Glatter O (1991). Optical sizing of small colloidal particles: An optimized regularization technique. Appl Optics 30:4889-4896.

Spurej E, Glatter O, and Pfeiler G (1992). Shape change of human blood platelets: Reliable and fast detection by quasielastic light scattering. Experientia 48:71-79.

Tablin F, Oliver AE, Walker NJ, Crowe LM, and Crowe JH (1996). Membrane phase transition of intact human platelets: Correlation with cold-induced activation. J Cell Physiol 168: 305-313.

Vanhoutte PM (1981). In: DeClerck F and Vanhoutte PM, editors. 5-Hydroxytryptamine in peripheral reactions. New York: Raven Press, 163-174.
White JG (1968). Effects of heat on platelet structure and function. Blood 32:324-335.

White JG (1991). The cytoskeleton of human blood platelets. In: Harris JR, editor. Blood cell biochemistry, vol 2. New York: Plenum Press, 113-148.

White JG and Krivit W (1967). An ultrastructural basis for shape changes induced in platelets by chilling. Blood 30 : 625-635.

White JG and Rao GHR (1998). Microtubule coils versus the surface membrane cytoskeleton in maintenance and restoration of platelet discoid shape. Am J Pathol 152:597-609.

Winokur R and Hartwig JH (1995). Mechanism of shape change in chilled human platelets. Blood 85:1796-1804.

Zatloukal K, Sohar R, Lackinger E, and Denk H (1988). Induction of heat shock proteins in short-term cultured hepatocytes derived from normal and chronically griseofulvin-treated mice. Hepatology 8:607-612.

Zucker M and Borrelli J (1954). Reversible alteration in platelet morphology produced by anticoagulants and by cold. Blood 9:602-608.

Zwaal RFA, Comfurius P, and Bevers EM (1998). Lipidprotein interaction in blood coagulation. Biochim Biophys Acta 1376:433-453. 